\title{
EDUCATION IN THE VALUE SYSTEM OF THE FUTURE EDUCATORS
}

\author{
M. Teneva* \\ Faculty of Education, Trakia University, Stara Zagora, Bulgaria
}

\begin{abstract}
Education is one of the eternal human values. Its role for the professional realization and the development of the person is unquestionable. It is in a positive correlation not only with the development and improvement of the individual, but it also has a peculiar influence on the quality of life and the prosperity of society in a global aspect.

The object of the present study is the value system of the future teachers.

The aim of the study is to outline the components in the value system of the future teachers and the place of education among those components.

For the realization of the objective, a test-questionnaire was used.

The survey covered 50 students majoring in Social Pedagogy who are educated and trained in the Faculty of Education at Trakia University.

The results show that the value system of the future teachers is oriented towards eternal and spiritual values.

The dominant components in this system turn out to be: health, family, friendship, education, honesty, art.
\end{abstract}

Key words: education, value orientation, value system, teacher

\section{INTRODUCCTION}

In today's globalized world, the young person in Bulgaria is facing serious challenges.

On the one hand, he or she seems to be feeling free in the highest possible degree due to the fact that a number of limitations of the previous social order have been eliminated for a long time already.

On the other hand, there is a feeling that young people do not take full advantage of this basic human right.

The information flow that pours over the young person daily is so luxuriant and diverse that in many cases he or she falls into a state of helplessness. This position is reinforced by the conditions of antagonism, by the situations of the world's political, ethnic and religious conflicts and by the economic crisis in which young people are forced to survive.

The young people are confused when choosing their values, their close social environment; when establishing their behavior in shaping relations, in the selection of a strategy for self-

\footnotetext{
${ }^{*}$ Correspondence to: Maria Teneva, Faculty of Education, Trakia University - Stara

Zagora, Bulgaria, m.s.teneva@abv.bg
}

actualization and effective operation in the social world.

This puts the person in a state of stress and helplessness.

The deformations in society have a fatal effect on the choices which the young person makes. They also affect to a great degree his or her value orientation and the organization of their values in a system.

\section{METHODOLOGY OF THE RESEARSH:}

For the realization of the objective of the study, a survey was performed with 50 students majoring in the specialty Social Pedagogy who are trained at the Faculty of Education at Trakia University, Stara Zagora.

The students were asked to complete a specially designed test-questionnaire. All submitted questions are open-ended, with the option of constructing answers of their own.

In order to provoke the students to be honest and trustworthy in the formulation of their responses, they were given the opportunity to fill in the test anonymously. 


\section{EDUCATION AND VALUES}

The problem of the value system of the young person in the modern world stands with exceptional sharpness and significance. What that person regards as valuable and what guides him or her in their life determines the specifics of the personal relationships, their beliefs, attitudes, the way of functioning of the society, the personal choices, achievements and ambitions.

Values are defined as "phenomena or objects of material or spiritual nature which are considered to be significant for the individual. They are related to addressing the needs of the individual" (1).

The social world is made up of tangible and intangible resources that are in a complex interaction. In their everyday life, people enter relationships with the components of the environment and function there on different levels. Each individual not only gets to know the properties of objects and phenomena but also evaluates them on his or her own terms and defines them as significant or insignificant, good or bad for his life, for the society or the nature.

The determination of the values is in a close relationship with the individual's needs.

The need can be perceived by the individual as a need of which he or she is aware (a tested deficit) of something in the actual moment of its existence.

As Y. Merdzhanova states, they (the needs) "stay behind (before) the behaviour as a need, a necessity for something" (2).

Human needs are characterized by dynamism and the existence of multiple layers. They vary widely, due to the uniqueness of each individual personality. At a certain time span and situation, different people have different needs. The satisfaction of some needs creates new ones which leads us to the realization that the process is characterized by infinity.

E. Maslow (representative of the humanistic psychology) organizes the basic needs in a hierarchical pyramidal structure. At the base of the pyramid he puts the physiological needs such as food, water, air and sleep, without which the existence of a living organism is impossible. Following them are the existential needs: of shelter, safety, security, belonging and love. The social needs are: communication, affection, concern for the others, attention to one's own self. The so called prestigious needs, according to him, are: respect and self-esteem. The highest needs in E. Maslow's pyramid are the needs of selfrealization, of self-actualization (3).

Depending on what level of the personal development an individual is, the specifics of their needs are determined. The satisfaction of these needs provokes a man to perform certain actions, creates the nuances of his or her relationship with the components of the natural and the social environment, and determines his or her value orientation.

Without a constructed value orientation, the person cannot realistically assess the actions and the reactions of the surrounding environment of people and would easily succumb to insinuations and provocations or would follow a mimetic pattern of behaviour, which automatically leads to difficulties in finding their identity and determining their place in the social world.

A coherent set of those material or spiritual values that the person identifies as significant for his life forms its value system. It is a standard to guide human behaviour in different situations.

Values have a dynamic character. They change during different periods in the development of the individual under the influence of the degree of personal development, the differences in the perception and the person's relation to the world, the phenomena and events taking place in it, under the influence of a complex interaction of genetic factors and the social environment.

This dynamics can be caused as a result of the changed conditions in which the person is forced to operate. In a period of material, social or spiritual crisis, the personality reassesses his or her value system. At such times, the individual tends to ignore some values from a higher hierarchical level and to direct his or her efforts towards those values that are related to the satisfaction of the requirements of the first floors of the pyramid structure of the human needs of Abraham Maslow.

The so stated view is shared also by $\mathrm{Kr}$. Baytchinska. She launched the idea according to which in a moment of transition (a social crisis) some values give way to other values in significance which, if the person operates in "normal times", stand on lower floors in the hierarchy of values.

As Kr. Baytchinska puts it: "extreme conditions cause "the evacuated of content" of 
a number of values which have been important before" (4).

Considering the fact that for the last 26 years Bulgaria has been going through a period of social, economic and spiritual crisis caused by the transition from totalitarian to a democratic social order, we can imagine what kind of catharsis the person is experiencing, forced to operate under such conditions.

For much of the population of Bulgaria, the values are reduced to the satisfaction of basic vital needs. All the energy and the potential of the majority of the people are focused on their survival.

They are prevented from reflecting upon and accepting the eternal spiritual values, or in the event that have already formed those, living in the conditions of a crisis has caused the decline in their value system and as a result the values of the high levels of the hierarchical structure receded their place in terms of importance to such values that occupy a lower position in the hierarchy of needs.

The economically developed societies have long ago overcome the low positions which are bound to the meeting of the physiological and existential needs of the individual. In such societies, the collective energy is directed to the full satisfaction of the prestigious and spiritual needs. The personality is supported to understand and accept the cultural values, the moral values, the spiritual values.

Education has always been an intrinsic value which has a key role in the development of the society. It is related to the formation of knowledge, skills and competencies and is relevant to the personal development; it is also directed to the full functioning of the individual in the society and the labour market. As M. Andreev points out, "education plays a crucial role in the life of any society because it provides important prerequisites for its full reproduction"(5).

With the development of the productive forces, the social relations become more complicated and this in turn requires increasing the requirements put before education.

There is a close relationship between the school, educational and the economic progress of society. In confirmation of this statement is the opinion of D. Vassilev, in whose opinion, "Education is realized through the activities of the school institution. The school is the bridge between science and industry ... The educational system as a social phenomenon is called to meet the educational, cultural and professional needs of the society through the tasks and functions assigned to the educational institutions of low, medium and high level"(6). In order to develop our society in the right path, our efforts need to be directed towards the implementation of an effective educational process. This could be realized with the support of teachers, spiritually and morally towering personalities devoted to the cause of education.

Along with the family and social environment, the school is an important factor shaping the value system of children, adolescents and young people.

The peculiarities in the value system of a teacher are projected on the value system of his or her graduates.

This fact provoked our research attention to the differentiation of the components in the value system of the future teachers.

\section{RESULTS}

The surveyed students majoring in the specialty Social Pedagogy, studying at the Faculty of Education at Trakia University, willingly completed a specially designed testquestionnaire. That the test was given to be anonymously filled in contributed to their conscientiousness and their sincerity in formulating their answers.

The purpose of the first question was to highlight the leading motives that provoked the young people to continue their education at the university. Our intention was to determine whether their choice was purposeful, meaningful, voluntarily or influenced by random factors.

From the specifics of the concrete answers to this question we found out that the future social educators understand the importance of education for the prosperity of the individual, but at this stage still a small number of them can see its projection on the prosperity of society in a global aspect.

The students do not point out random factors that have provoked their personal choice for the continuing of their education.

The answers formulated by the students can be selected in several groups which have the following expression in percentages:

The largest share of the surveyed students $44 \%$ - are motivated to continue their education at the university because they are confident that higher education is positively correlated with professional development and the realization of the personality. 
$31 \%$ of the future teachers believe that the accumulation of more knowledge, skills and competences is projected on the personal development and contributes to one's full realization not only professionally, but also socially.

$11 \%$ of the respondents find a causal connection between raising the level of the educational status and the increase of the prestige of the individual.

$8 \%$ of the students stand for the idea that education is a value of social importance. In their reasoning, they go beyond the individual benefits of the educated person. They look at the positive aspects and their potential contribution resulting from the acquisition of higher education and performing highly professional work for the development of society. They believe that this will make them more useful to themselves and the others and will contribute to improving the quality of life of the entire society.

For $6 \%$ of the surveyed students, increasing their education is inspired by the pursuit of self-knowledge and self-affirmation. The students indicate that they have accepted the challenge to continue their education at the university in order to establish the extent to which they know themselves, to ascertain whether they are able to overcome difficulties, to check if they can follow consciously the path they have chosen and to bring to a fruitful end the challenge they have committed themselves to, to establish whether they can change their lives for the better.

The so differentiated by the future teachers motives for continuing their education give us reason to conclude that each of them has made a voluntary and deeply meaningful choice. Leading are the motives for personal and professional development and fulfilment. A small share occupies the motive of prestigious motivation and the motivation to receive knowledge of one's own self. No one has indicated that their motivation to study is the desire to occupy positions of power or and to obtain financial incentive.

With the second question the students were required to identify the values that they unconditionally accept and that are part of their value system.

In none of the cases transient values such as money, power, or other components of the material world were mentioned.
The future teachers tend to be directed to the selection of timeless spiritual values - such as family, friendship, health, education, cultural traditions, freedom;

moral values - honesty, fairness, loyalty, altruism, responsibility;

Christian values - love, kindness, empathy, compassion, mercy, intolerance to slander and injustice.

All of the students who took part in the study $(100 \%)$ defined education as the supreme human value.

For $4 \%$ of them, being educated is not only an intrinsic and timeless value but also a significant choice that every human being must consciously and voluntarily make in their lives.

$12 \%$ of the future social pedagogues differentiate the presence of a correlation between education and the evolution of society in their replies.

In $18 \%$ of the cases, the prospective teachers indicate that the higher education contributes to a better adaptability of the individuals and contributes to their full realization.

$32 \%$ of the surveyed students find a correlation between education and personal development. They point out that education is a key factor supporting the full development of the natural potential and the development of the personality.

$44 \%$ of the responses indicated that education is the most valuable investment that a person can make at this moment with a projection to the future.

The purpose of the third question was to establish whether the answers to the above questions are declarative, formulated rather as we would like them to sound, or whether they reveal the real state of the problem, refracted through the consciousness of the future social pedagogues.

We asked the students to present in the form of a scheme the relationship between the components "education - personality".

In $38 \%$ of the cases, the students present a scheme comprising two components. This group of students found a correlation between education and profession. The following schemes were established:

education - professional competence of the person education - professional qualifications of the person 
education - professional development of the person

$36 \%$ of the future social pedagogues present a scheme which includes three components. Logically, they bind education both with the professional, as well as with the personal development of the individual. The diagram which the students presented contains the following components:

education - professional development personal realization

$15 \%$ of the students construct a logical scheme comprising four components. In this group of students a new component can be observed the high material reward for exercising highly qualified labour. The fact that they do not perceive the material reward as an end in itself but as a means of satisfying their needs leaves us with a positive impression. The students justify this relationship with the confidence and the prestige of the individual.

The presented four-component logical schemes are in the following variations:

education - profession - occupation professional realization - contribution of the individual to the society

education - professional work - high payment - personal prestige - self-respect realization of the self

education - skilled labour - higher payment - confidence of the personality

education - professional realization - high payment - a high standard of life of the individual

$21 \%$ of the surveyed students present a logic scheme containing more than four components. In search of the causalities and relations, they found a correlation between education and the self-concept of the personality. The following varied types of established schemes can be observed:

education - profession - job - career contribution of the individual to society education - professional competence - work requiring a special qualification - personal prestige - self-esteem - self-actualization education - competence - professional development - contribution of the individual to society - confidence - prestige - high personal self-evaluation

\section{CONCLUSION}

As a result of the study that was performed, we reached the following conclusion:

The future social pedagogues have a well formed value system which is oriented towards timeless and spiritual values. This in its own way could contribute to their successful professional realization in the humanitarian profession they have chosen.

Education is viewed by the students as the supreme human value, to which the person should aspire. It occupies a key position among the components in their value system.

The students of the specialty Social Education find a correlation between education, the realization of the individual in a professional and social aspect and the prosperity of society.

\section{REFERENCES}

1. Novikov, A. M. (2013) Pedagogy: dictionary of systems of basic notions. Russian Academy of Education. Moscow.

2. Merdzhanova, Y. (2012). European career education in Bulgarian conditions. Pedagogy year LXXXIV, Book 1. Main version of pedagogical publications MES. 79. Sofia

3. Maslow, E. (2002). Motivation and personality. Publishing House Prosveta. Sofia

4. Baytchinska, Kr. (1994). Values. Value stress. Crisis of values. Academic Publishing House Marin Drinov. Sofia

5. Andreev, M. (1998). Education and Society. Educational Sociology. Sofia

6. Vasilev, D. (2008). Experimental pedagogy. Publishing House Daniela Ubenova . Sofia 